\title{
O DESERTO NA GOTA: TENSÃO E CRUZAMENTOS EM “ESTALACTITE”, DE CARLOS DE OLIVEIRA
}

\author{
Aline Duque Erthal
}

\begin{abstract}
RESUMO
Em $O$ aprendiz de feiticeiro, Carlos de Oliveira diz ser o deserto uma "obsessão" da poesia portuguesa moderna. No mesmo texto, uma equaçáo indica que esse "deserto" é passível de leitura mesmo quando tal vocábulo não se imprime no papel. Propóe-se, então, o conceito de função deserto, e observa-se, neste artigo, uma das imagens que melhor o condensam: a extremidade de uma estalactite.
\end{abstract}

PALAVRAS-CHAVE: Poesia; Carlos de Oliveira; deserto.

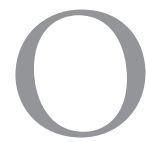

encerramento de um dos mais conhecidos textos de Carlos de Oliveira ("Na Floresta", publicado em $O$ aprendiz de feiticeiro) traz algumas chaves importantes para se pensar boa parte da poesia produzida em Portugal no século 20 - não apenas retroativamente à data de impressão do livro (1971), mas sobretudo cataforicamente: o texto de Carlos de Oliveira diz muito também sobre o que a ele sucede - "modernidade avançada", "tardia", "pós-modernidade" ou, simplesmente, ainda "modernidade":

1 Sobre a pertinência da continuidade do termo, leia-se a diferenciaçáo de modernidade em relação a modernismo, feita por Fernando Pinto do Amaral já no primeiro capítulo de $O$ mosaico fluido: "A minha ideia pessoal corresponde ao que penso ser a visão predominante em Portugal: assim, creio que, em linhas gerais, enquanto sob a cómoda protecção do termo modernidade - concebido, é claro, neste caso, como um período historicizável - podemos dar abrigo a um vasto panorama de transformaçóes sócio-culturais englobando a filosofia, a política, as artes, as letras, etc. e correspondendo a uma crise, mas também, por isso mesmo, a um esforço renovador ou revolucionário cujo início ou fim são polémicos e dificilmente situáveis, já, em vez disso, reservaria a designação de modernismo para uma série de mo- 
A poesia portuguesa, sobretudo a moderna, está cheia de desertos. Deserto é uma palavra chave, uma obsessão, como podia provar facilmente. Mas descansem. Limito-me a propor a seguinte identidade mais ou menos algébrica:

floresta $=$ labirinto

labirinto $=$ deserto

deserto $=$ floresta

Quod erat demonstrandum.” (OLIVEIRA, 1973, p. 202)

Para além de assinalar a frequência de um vocábulo (uma palavra-chave, "deserto"), o texto propõe uma identidade algébrica ${ }^{2}$, que chama a atenção para dois pontos fulcrais: a liberdade reclamada pelos significantes em relação aos significados (posto que as palavras podem se corresponder, ainda que suas formas sejam distintas entre si), ou seja, a instauração de um novo tipo de referencialidade, que náo se obriga a uma colagem com um suposto real

vimentos ou tendências estéticas muito mais balizados no tempo (quase sempre entre as últimas décadas do século XIX e os anos 20 ou 30 deste século [XX], muito variáveis consoante os países e as culturas, e cujas repercussóes actuais, embora por vezes determinantes, podemos já considerar razoavelmente desvanecidas" (AMARAL, 1991, p. 19). Mais adiante, o autor cita Jorge de Sena, para quem "Modernidade, sem mais, é ser-se do tempo em que se vive", e "'Modernismo foi a fase dupla - pós-simbolismo e vanguardismo - que durou desde c. 1910 a c. 1959"” (AMARAL, 1991, p. 19).

Em Carlos de Oliveira, lemos "modernidade" nesse sentido mais lato, que acaba por englobar também a pós-modernidade se considerarmos pós como Fernando Pinto do Amaral, para quem o prefixo "é capaz de, ao dar conta de uma mudança, deixar no ar a ideia de um prolongamento sem fim". Dessa noção de prolongamento, interessa-nos a ideia de "a partir de", ou, mais propriamente, a rejeição da suposta "vontade de superação do passado", "um iconoclasta desrespeito pela maioria das tradiçôes", "de ruptura em ruptura, de negaçấo em negação" que muitas vezes se atribui à modernidade. "Não há revoluções literárias que rompam cerce com o passado. [...] cortes totais, rupturas, não se dão.", escreve o poeta (OLIVEIRA, 1973, pp. 263-264).

2 Em matemática, uma equação é a afirmação de que duas expressóes são iguais e permanecem iguais. As equaçóes que são verdadeiras para todos os valores das variáveis envolvidas (como em $\mathrm{a}+\mathrm{b}=\mathrm{b}+\mathrm{a}$ ) são chamadas "identidades" - e é desse tipo de equação que Carlos de Oliveira nos fala, indicando que, onde se lê floresta, pode-se ler labirinto e pode-se ler deserto (o que não tira, evidentemente, a importância da forma escrita para o poema, a precisão de escolha de cada vocábulo; daí a proposição ser "mais ou menos" algébrica). O uso das variáveis permite generalizações, fazendo com que equaçóes ou desigualdades sejam formuladas como leis. A variável é capaz de representar um valor ainda não conhecido, a ser encontrado com a resolução da equação. 
pré-discursivo e inequívoco; e o apontamento para um espaço de relaçóes, que, embora possam se condensar momentaneamente em uma de suas facetas (em um verso, labirinto; em outro, floresta; e daí por diante), são irredutíveis a qualquer uma delas. Essas relaçóes permanecem circulando, potentes, em uma ideia de movimento reforçada pela escolha dos vocábulos exemplares para representar a equação: labirinto, floresta e deserto associam-se, até pelo texto em que se insere a proposição de sua identidade, à errância, à perda e à multiplicidade.

O que é demonstrado pela equação é, então, a prevalência de um deserto que não pode ser entendido apenas em seu sentido referencial (até porque, embora a palavra "deserto" seja, de fato, frequente na produção do século 20 , ainda fica bastante atrás em número de apariçōes de lugares como "mar", "cidade", "corpo" e, muito provavelmente, dos próprios "labirinto" e "floresta"), mas sim passível de leitura mesmo quando o vocábulo "deserto" ou seus orbitantes (aridez, areias, dunas) não se imprimem no papel. Como um traço a se desprender de poética para poética, esse deserto multiplica-se em uma teia. Ultrapassa a nomeação referencial (está entre os nomes, fora deles; é o ziguezague) e também ultrapassa cada autor; está entre eles, fora deles, como o "céu que interceptasse vários textos" de que nos fala Luis Miguel Nava ${ }^{3}$.

Quando diz ser o deserto a obsessão da poesia moderna portuguesa, portanto, Carlos de Oliveira se refere menos à paisagem caracterizada pela aridez, com precipitaçóes atmosféricas irregulares ou escassas e vegetação rara, que apareceria nomeadamente ou descrita nos poemas (seja como cenário para o desenrolar de uma ação, seja como metáfora para estados de espírito individuais ou coletivos), e mais a um espaço de - utilizamos expressóes de Deleuze - estouramento dos estratos, aberto ao fluxo e comunicação de intensidades, efeitos, relaçôes. Então, para observar mais de perto essa "obsessão", importa não tanto seguir a trilha de significantes como "deserto", "aridez" ou "deser-

3 Acerca de determinadas imagens poéticas, o autor escreve: "[..] pressentimos que essas imagens subterraneamente se articulam, como se entre si estabelecessem nexos a partir dos quais formassem uma constelação num céu que interceptasse vários textos. Dir-se-ia que as anima uma energia que lhes é comum e, como se os seus fios em determinados pontos se cruzassem, conferindo à obra em que se inserem uma superfície semelhante à dos sofás capitonnés, há qualquer coisa de inquietante em imaginarmos que através dessas fulguraçôes as obras comunicam todas entre si. (NAVA, 2004, p. 57). 
tificação", mas perseguir imagens e processos que escrevem um esvaziamento e deserçóes do conhecido, bem como perceber como esse vazio instaurado poeticamente não funciona apenas com sinal de negativo: ele representa a possibilidade do múltiplo, o canal de trânsito, atravessamentos e passagens, a abertura para outros (sujeitos, configuraçóes de mundo, linguagens).

A esse esvaziamento produtivo, que se faz temporal, subjetiva e materialmente, chamaremos de função deserto ${ }^{4}$. Em matemática, "função" representa um valor que depende de outros, e do qual esses outros também dependem. Trata-se, então, da peça de uma relação que não cessa de se fazer ${ }^{5}$. As formas com que essa função se produz e se concretiza na linguagem são diversas, sendo as imagens de fendas, brancos, vazios, espaçamentos, silêncios e entre (como um fora que se faz não meramente com o dentro, mas no dentro) algumas das mais profícuas. Os nós irradiadores a costurar figuras tão díspares constituem algumas das características principais da função deserto, que são: 1 . desertação do conhecido, do habitual e do estável, sem, no entanto, prescindir da referencialidade; 2. desertificação espaço-temporal (figuração de desertos, areias, dunas, secura, espaços abandonados; inscrição do branco, do silêncio, do vazio e da falha, fresta, buraco ou sulco; rasura ou problematização radical da memória individual ou coletiva); 3. cruzamentos espaciais, temporais, subjetivos e materiais ${ }^{6}$.

4 Conceito a ser desenvolvido em minha tese de doutoramento, que identificará como o deserto enquanto função poética se constrói em imagens diversas elaboradas por Carlos de Oliveira, Luis Miguel Nava e António Ramos Rosa.

5 Como a variável, a função é um elemento que não tem valor em si - este permanece suspenso, irredutível a qualquer uma de suas facetas, apenas condensando-se momentaneamente a cada operação. Nunca se pode afirmar: x é sempre igual a 12, ou a função de y é sempre 22 , ainda que x possa ser igual a 12 em infinitas equaçóes, e a função de y possa ser 22 em infinitos gráficos.

6 Saliente-se que a função deserto não coincide com o termo modernidade. Essa função poderia ser tomada como um dos aspectos da modernidade em seu sentido mais lato (que, tal como se observa na nota de rodapé de número 2 , abarca muito do que se conceitua comumente como pós-modernidade, conceituada como esforço renovador que náo se apoia em rupturas, mas em construçóes a partir de). Mas, mais do que um aspecto, a função deserto talvez seja simultaneamente o lugar de onde os esforços modernos se constroem (as falhas, que constituem paradoxalmente corrupção e pertencimento em relação ao que está posto) e o lugar buscado por esses esforços (um novo que também é a um só tempo "corrupção e pertencimento em relaçáo ao que está posto"). Esses dois lugares (partida e chegada) reúnem-se na função deserto, como um espaço vazio e múltiplo em permanente atualização, permanen- 
Um momento-chave da produção de próprio Carlos de Oliveira oferece a oportunidade de se observar uma das maneiras de essa função deserto se concretizar: o poema "Estalactite", de Micropaisagem - livro que, publicado em 1968, é considerado por poetas e críticos como António Ramos Rosa, Eduardo Prado Coelho, Américo Lindeza Diogo e Osvaldo Silvestre um marco de viragem da produção do poeta (cf. MARTELO, 1996, pp. 261-263). Micropaisagem é especialmente interessante na medida em que, como observa Rosa Maria Martelo, representa a culminação de "uma tendência para o despovoamento da paisagem poética" que vinha se desenvolvendo desde Colheita Perdida: "o lugar que na primeira versão de Turismo era ocupado pelas paisagens sociais tenderá a ser ocupado por paisagens progressivamente mineralizadas e rarefeitas, embora metonimicamente generalizantes" (MARTELO, 1996, p. 311). O poema concretiza outro tempo, outro movimento e outro som, sem deixar de permanecer ligado ao real - até porque o texto, ele mesmo, assinala a todo instante sua própria realidade. Cria-se um novo no qual linhas dicotômicas (passado e futuro, atual e virtual, referencial e não referencial) escapam de suas rotas tradicionais e se atravessam, oposiçóes binárias conceituais ou imagéticas caem por terra, transformando-se em possibilidades, múltiplos sem um. Esvaziando qualquer acepção unificadora de real, a poesia reconhece o que, nele, há de móvel e plural.

\section{A tensa construção}

O poema inaugural de Micropaisagem toma emprestado não apenas o nome, mas também processos da "forma colunar pendente do teto das cavernas ou subterrâneos, resultante da precipitação de bicarbonato de cálcio, trazido em dissolução na água”, definição do Houaiss para estalactite. Composta de carbonato de cálcio (calcita), ela é, junto com as estalagmites, dos espeleotemas mais conhecidos e comumente encontrados em cavernas. Sua formação deriva de um jogo; tensão extravagante entre a força de adesão ao teto e a atração da queda, o passado e o futuro:

temente outro. O que procuramos espreitar é esse campo plural e difícil de descrever, que pode, como temos dito, se condensar em palavras diversas, como labirinto, mar, espelho e o próprio deserto. Se, para isso, apoiamo-nos na palavra "deserto", não é apenas por esta ser uma eleição do próprio Carlos de Oliveira, mas porque ela afigura-se como a mais apropriada para nomear esse "isto" (lembramo-nos do título do livro de Pedro Serra sobre Ruy Belo, Um nome para isto) de que pretendemos nos aproximar. 
As águas de chuva, aciduladas pelo gás carbônico da atmosfera e do solo, ao penetrar pelas fraturas da rocha calcária, vão dissolvendo-a e transportando o bicarbonato de cálcio em solução até emergir no teto de uma caverna preexistente. A gota dessa soluçáo aquosa fica pendurada no teto até que atinja volume e peso suficiente para vencer a tensão superficial, força de adesâo, e cair. Nesse período, já no espaço da caverna, aquela solução é submetida a condiçôes muito distintas das anteriores, quando percorria, sob pressão, as estreitas fraturas da rocha. Essa mudança de condições - maior ventilação, alteração de temperatura, $\mathrm{pH}$, pressão de $\mathrm{CO}_{2}$ - gera o desequilíbrio químico da solução pela liberação do gás carbônico no ambiente da caverna, com a consequente precipitação de parte do bicarbonato dissolvido. Formam-se assim, na superfície da gota, área de maior desequilíbrio, os primeiros cristais de calcita que, ordenando-se ao longo do contato da gota com o teto, dâo origem a um anel cristalino o qual servirá de base para a futura estalactite. Gota após gota, o processo tem continuidade, formando-se uma estalactite tubular e oca, que cresce em sentido descendente. A gota, ao cair, ainda carrega consigo bicarbonato em solução, o qual vai sendo depositado em capas sucessivas no piso logo abaixo, formando uma estalagmite. O crescimento oposto da estalactite e da estalagmite faz com que essas peças muitas vezes se unam dando origem a colunas. [Grifos nossos]. (LINO, 2009, pp. 125-126)

Resíduos inverossímeis espacializam a duração e testemunham a transgressão da mais elementar das leis: a gravidade. Acumulados, materializam um movimento. Caem, mas, como em desafio, manifestam concretamente esse cair. Escultura de queda, a estalactite tem no intervalo (de espaço/tempo) sua condição; exibe sua formação de calcita, mas é principalmente a falta o que fica em evidência: os espaços vazios em suas laterais, o provisório lapso entre sua extremidade e o chão, o oco da coluna descendente.

Em suas 24 partes numeradas (das quais este artigo tratará apenas de alguns fragmentos), o poema de Carlos de Oliveira também se precipita em 
movimento vertical. Rolam palavras, imagens, versos, uns sobre os outros, acumulando e deslocando sedimentos. Gotas de "água ou pedra” (p. 209): palavras que (pesadas, densas) quedam pendentes. Tensão de imobilidade vibrante, em espaço "gradualmente espesso" (p. 217).

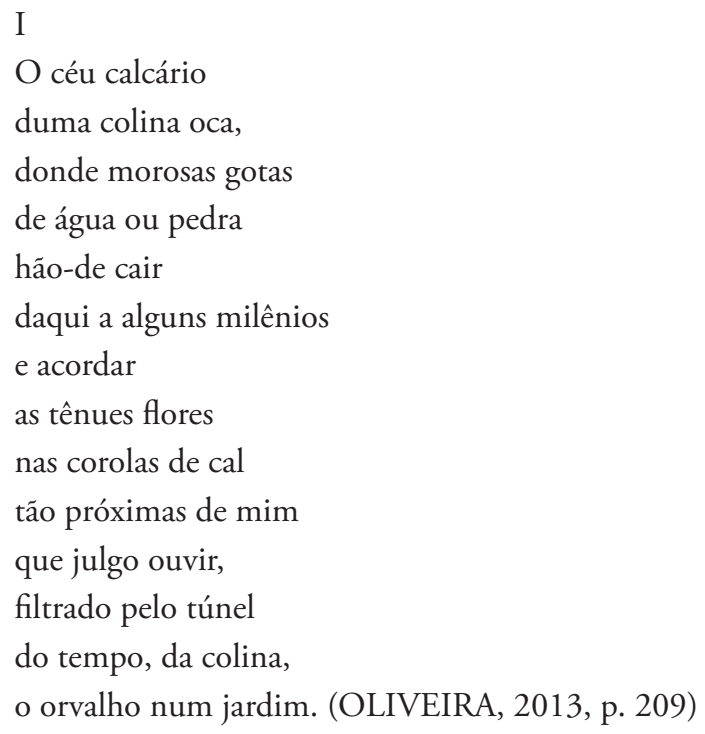

O poema começa em gotejamento - marcado pela reiteração em intervalos curtos do fonema $/ \mathrm{k} /$ e a tendência paroxítona dos versos do início do poema - e forma graficamente, na redondez do "o" e na sequência côncava da letra c nos primeiros versos, o que poderia ser a base da coluna descendente. O gotejamento torna-se progressivamente descontínuo a partir do sexto verso: os intervalos entre /q/, de daqui, e /k/, de acordar, corola de cal e colina, são irregulares, como se a queda se tornasse mais espaçada, deslizando até uma cristalização - provisória. O movimento é observado também em macroescala, na formação estrófica ao longo de todo o poema. Os primeiros textos arredondam-se: têm maiúsculas no início, pontos finais no fechamento. A partir da $12^{a}$ parte, as estrofes encavalgam-se, com períodos que começam em uma e terminam em outra, alongando o oco da coluna que, em subversão, cai, mas cristalizando seu passado e antecipando flores futuras de cal(igrafia). 


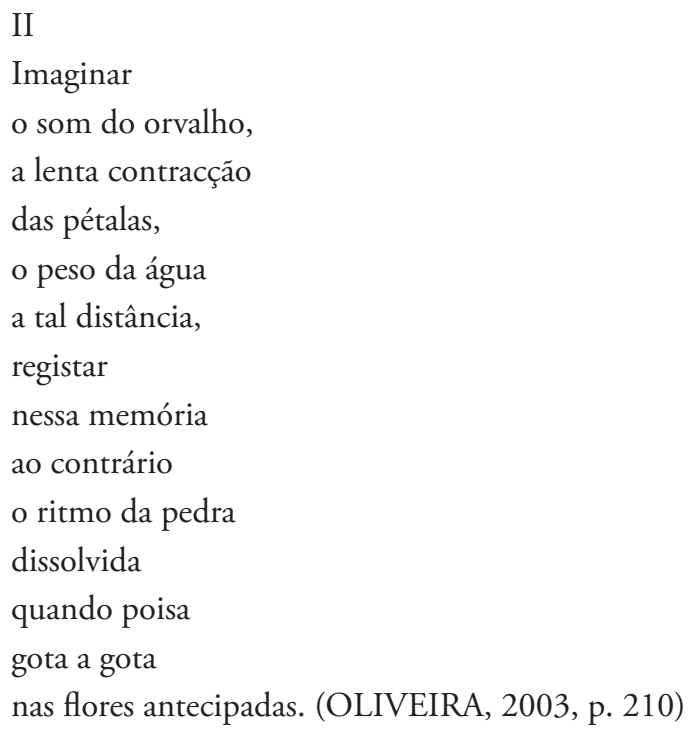

Como estalactites em progresso para estalagmites, o poema é memória e "memória ao contrário", registra e antecipa: imagina. Tal como no processo cal-igráfico (estalactite), no caligráfico (poema) imagens são gotejadas para, adiante, se repetirem, arrastadas e reconfiguradas: palavras "rolam / de verso / em verso" (p. 216), o som é transmitido "de flor para flor" (p. 217) no poema-estalactite ${ }^{7}$. Esse arraste carrega também o processo de leitura do poema para

7 Note-se, como exemplo, que a parte II é citada (reescrita/reelaborada), de forma dispersiva, nas partes de IX a XIII. "Imaginar / o som do orvalho,", principia a parte II, e, de forma idêntica, a parte IX; Os versos seguintes da parte II são "a lenta contracção / das pétalas,", que reverberam nos primeiros da parte X: "A lenta / contracçáo / das pétalas,”. Os versos na sequência imediata da parte II, “o peso da água / a tal distância," rolam para o início da parte XI: “O peso / da água / a tal distância”. É a este movimento que o poema obriga a leitura: XII

Registar nessa memória ao contrário de trás para diante as palavras que ficam assim misteriosas 
um cotejamento obsessivo, em movimentos retrospectivos e antecipatórios pelos versos do texto. O embaralhamento de passado, presente e futuro dá-se ainda em combinaçóes inusitadas de verbos, advérbios, adjetivos e substantivos ligados a diferentes campos temporais [grifos nossos]: lêem-se as "flores antecipadas" (p. 221) e "as flores / adiadas na cal” (p. 232), "o poema sonha / o arquétipo / do voo (p. 214); "O pulsar / das palavras [...] lembra / o das estrelas / antes / de caírem" (p. 215); "o impreciso / som / milénios depois / [ou antes] / de se ouvir”. (p. 228) $)^{8}$. É, portanto, a "frágil espessura / do tempo" que

e depois
soletrá-las
do fim
para
o princípio,

XIII

olhá-las

como imagens

no espelho

que as reflecte

de novo

compreensíveis

e tornar

a juntá-las

obsessivamente

ao ritmo da pedra

dissolvida

quando poisa

gota a gota

nas flores antecipadas,

[...] (OLIVEIRA, 2003, pp. 220-221).

8 No poema/estalactite - ou, mais apropriadamente, em sua ponta, na gota que oscila no limiar mais indecidível entre queda e adesão -, tempos se cruzam, atual e virtual coexistem, vazio e concretude são reversíveis, real e imaginário se indistinguem. Essa micropaisagem-limite, ponta/ponto que é um "menor circuito interior", aproxima-se da imagem-cristal, no livro $A$ imagem-tempo: "Com efeito, não há virtual que não se torne atual em relaçâo ao atual, com este se tornando virtual sob esta mesma relação: são um avesso e um direito perfeitamente reversíveis. São 'imagens mútuas', como diz Bachelard, nas quais se efetua uma troca. A indiscernibilidade do real e do imaginário, ou do presente e do passado, do atual e do virtual, não se produz portanto, de modo algum, na cabeça ou no espírito, mas é o caráter objetivo de certas imagens existentes, duplas por natureza [...] A imagem atual e sua imagem virtual constituem, portanto, o menor circuito interior, em última análise, uma ponta ou um ponto [...]" (DELEUZE, 2005, pp. 89-90). E, um pouco adiante: "O cristal, 
os versos põem em vibração. Trata-se de um desafio, deserigido (neologismo para falar desse outro deslocamento) por uma poética que é toda configuração de outros: outro tempo, outro movimento, outra matéria, outro som, outro espaço (o uso insistente do pronome verifica-se no próprio poeta).

\author{
III \\ Se o poema \\ analisasse \\ a própria oscilação \\ interior, \\ cristalizasse \\ um outro movimento \\ mais subtil, \\ o da estrutura \\ em que se geram \\ milénios depois \\ estas imaginárias \\ flores calcárias, \\ acharia \\ o seu micro-rigor. \\ IV \\ Localizar \\ na frágil espessura \\ do tempo, \\ que a linguagem \\ pôs \\ em vibração, \\ $o$ ponto morto \\ onde a velocidade
}

com efeito, não para de trocar as duas imagens distintas que o constituem, a imagem atual do presente que passa e a imagem virtual do passado que se conserva: distintas e no entanto indiscerniveis [...]. O cristal vive sempre no limite, ele próprio é 'limite fugidio entre o passado imediato que já não é mais e o futuro imediato que ainda não é (....), espelho móvel que reflete sem descanso a percepção em lembrança" (pp. 102-103) [grifos nossos]. 
se fractura e aí

determinar

com exactidão

o foco

do silêncio. (OLIVEIRA, 2013, p. 212) [Grifos nossos].

O poema oscila, vibra, pulsa, cintila: palpita nesses versos um movimento outro, nascido da ameaça de queda e fixação da água/pedra/palavra. "Escreve-se sempre em ponto morto", observa o poeta em texto de $O$ aprendiz de feiticeiro, "entre duas velocidades, a que se extinguiu e a que vai surgir" (1973, p. 195). O ponto morto se dá, então, justamente na fratura da velocidade, nos exatos lugar e instante entre. A locução "ponto morto" combina as noçōes de (micro) lugar e morte para instaurar esse movimento - "mais subtil", na expressão do poema, "fingido", na descrição do texto d'O aprendiz de feiticeiro - e determinar o lugar exato do silêncio. É aí que se ouve melhor a poesia.

Silêncio, fratura e entre formam, com os demais elementos que temos recolhido (cruzamento temporal, busca por outros), a nuvem de características daquilo que denominamos função deserto, que tem como uma das condensaçóes mais privilegiadas na poesia de Carlos de Oliveira a ponta, a extremidade da estalactite. Mais especificamente, no instante exato do rompimento da gota - pois a potência de silêncio também se associa à carga explosiva. Em $O$ aprendiz de feiticeiro, o poeta escreve:

Quanto mais depurada for a proposta [do livro] (dentro de certos limites, claro está), maior a sua margem de silêncio, maior a sua inesperada carga explosiva. A proposta, a pequena bomba de relógio, é entregue ao leitor. Se a explosão se der ouve-se melhor no silêncio." (OLIVEIRA, 1973, p. 261-262)

No microtempo da explosão, o passado de estalactite está presente e simultaneamente é transgredido pelo "impulso / elástico" de arrebentamento ao mesmo tempo, o futuro já cintila. Rompe-se com a estabilidade e instaura-se um lugar novo, desertando-se do habitual mas sem se distanciar do real - a micropaisagem é essa descoberta de mundos no próprio mundo, assim como a 
linguagem poética é descobrimento de linguagens na própria linguagem. Nesse microespaço, filtrado, depurado, localiza-se o "grau de pureza / extrema,"

$$
\begin{aligned}
& \text { insuportável, } \\
& \text { quando } \\
& \text { o poema } \\
& \text { atinge } \\
& \text { tal } \\
& \text { concentração } \\
& \text { que transforma } \\
& \text { a própria } \\
& \text { lucidez } \\
& \text { em energia } \\
& \text { e explode } \\
& \text { para sair de si: }
\end{aligned}
$$$$
\begin{aligned}
& \text { XVI } \\
& \text { não pode } \\
& \text { com mais silêncio } \\
& \text { oculto } \\
& \text { e entáo } \\
& \text { a força } \\
& \text { contraída } \\
& \text { age } \\
& \text { ao inverso } \\
& \text { do excesso } \\
& \text { em que se contraiu } \\
& \text { [...] }
\end{aligned}
$$$$
\text { (OLIVEIRA, 2003, pp. 223-224) }
$$

Pertencimento e diferenciação, essa ponta prestes al em pleno rebentar (o limiar fugaz entre uma condição e outra acentua o que há de micro nesse espaço/tempo) concentra a energia de explosão do poema e póe equilíbrio e coesão em crise: 


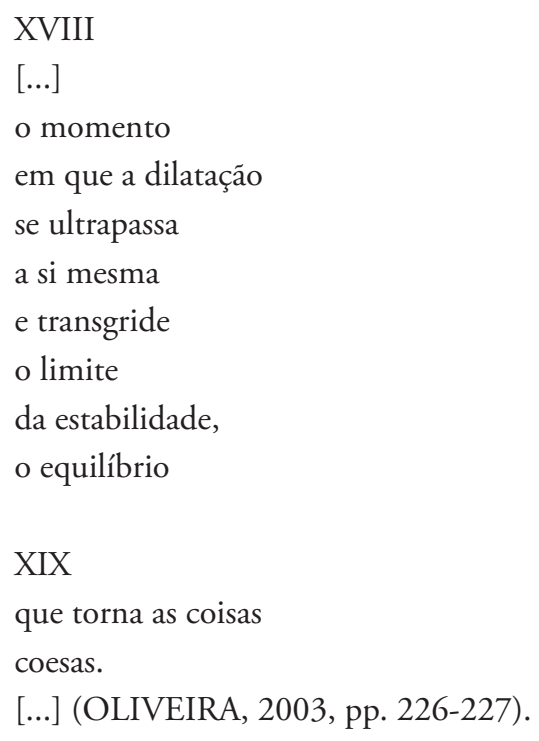

Desestabilizar relações de coisas e sentidos é desertar do ângulo habitual de visão, e adotar um novo ângulo é criar um mundo outro, ainda que com e no antigo. "Incline a cabeça para o lado, altere o ângulo de visão”, recomenda ao sujeito poético o inventor de jogos, em poema do livro Sobre o lado esquerdo e é o quanto basta para as estrelas, que pareciam não mais cintilar, rebentarem "num grande fulgor" (OLIVEIRA, 2003, p. 183).

Com efeito, instalar-se num grão de areia, como aconselha o inventor de jogos, não corresponde simplesmente a mudar de escala, mas a usar o microscópio de forma a transmutar o "micro" em "macro", isto é, a proceder por sinédoque generalizante, já que apesar da aparência diferente, a estrela e o grão de areia serão aproximáveis por homologia. No entanto, isto só é verdadeiro dentro de um idioma (uma rede de metáforas absolutamente coesa) e, também por isso, o que o "inventor de jogos" sugere é que o texto funcione como modelo, como invençáo capaz de descobrir. Passar para a "micropaisagem" significa jogar tudo no poder de redescrição do modelo, e o modelo só pode ser o livro como um todo: o livro-idioma que a si mesmo se deverá 
reescrever infinitamente para maior eficácia da redescrição. (MARTELO, 1996, p. 383)

Observar o universo com lentes de microscópio é, (ainda) em pleno real, desertar do conhecido, do estabelecido, do unívoco para abrir caminho para a multiplicidade do possível. Inventar re(d)escrevendo. A uma pergunta que poderia ter surgido no início deste texto, "Se é o deserto que se está perseguindo, e se a imagética de Carlos de Oliveira é tão profícua em paisagens desertificadas ${ }^{9}$, áridas, gandarenses, por que buscar a leitura do deserto em outra parte?”, responde-se: Porque é precisamente ali, no micro-rigor do lugar e do instante mais (in)tensos, onde se inscreve mais intensamente a função deserto em Carlos de Oliveira. O macrocenário da Gândara tem dupla desvantagem para a observação desse deserto poético: em primeiro lugar, é, embora metamórfico, em boa medida ainda reconhecível, faz parte de um repertório paisagístico. Seduzindo-nos com uma leitura ainda por demais referencial (o que não exploraria a expansão proposta pela equação deserto=labirinto=floresta), ele não se faz suficientemente outro, como o é a micropaisagem da ponta de uma estalactite. Além disso, em contraste com a vastidão gandarense, o espaço da gota se constrói pequeno para intensificar, concentrar, aumentar a densidade daquilo que, no poeta, pode aparecer também sob a capa da brevidade, secura, precariedade, pobreza, nudez, "grande solidão de areia", "carência de quase tudo", esses elementos de que "se sustenta bastante" toda a escrita de que o poeta é capaz” (OLIVEIRA, 1973, p. 264): um deserto que se quer não exclusão, mas potência de criação.

9 Em "Gás", texto de $O$ aprendiz de feiticeiro, o sujeito reflete criticamente acerca do desmatamento e da poluição em Portugal e no mundo: "O arboricídio floresce" (OLIVEIRA, 1973, p. 173); "A aridez desdobrada em cimento, pavimentos estéreis, fumegantes" (p. 174), "os operários trabalham nesta praça, aplicadamente, contra a clorofila. Lá embaixo, onde as avenidas desaguam no rio (afluentes de alcatrão em pedra), os esgotos, o lixo pela água dentro." (p. 174), "A desfolhagem instantânea das folhas no Vietname" (p. 176), "Nenhuma raiz viverá ali nos próximos cinquenta anos, pelo menos.” (p. 177), "Os operários derrubam a última tília e partem nos camióes pouco antes de se acenderem as lâmpadas da praça, que são (como os arboricidas gostam) flores de gás.” (p. 178). 


\title{
Referências
}

AMARAL, Fernando Pinto do. O mosaico fluido - Modernidade e Pós-modernidade na poesia portuguesa mais recente. Lisboa: Assírio \& Alvim, 1991.

DELEUZE, Gilles. A imagem-tempo. São Paulo: Brasiliense, 2005.

LINO, Clayton F. Cavernas: o fascinante Brasil subterrâneo. São Paulo: Gaia, 2009.

MARTELO, Rosa Maria. A construção do mundo na poesia de Carlos de Oliveira [tese de doutoramento apresentada à Faculdade de Letras da Universidade do Porto]. Porto, 1996.

NAVA, Luis Miguel. Ensaios reunidos. Lisboa: Assírio \& Alvim, 2004.

OLIVEIRA, Carlos de. O aprendiz de feiticeiro. Lisboa: Seara nova, 1973. . Trabalho poético. Lisboa: Assírio \& Alvim, 2003.

\section{DESERT IN THE DROP: TENSION AND CROSSINGS IN "ESTALACTITE", BY CARLOS DE OLIVEIRA}

\begin{abstract}
In $O$ aprendiz de feiticeiro, Carlos de Oliveira says that the desert is an "obsession" of modern Portugese poetry. In the same text, an equation indicates that this "desert" is readable even when this word is not printed on paper. It is proposed, therefore, the concept of desert function, and it is observed, in this article, one of the best images that condense this function: the end of a stalactite.
\end{abstract}

KEYWORDS: Poetry; Carlos de Oliveira; desert.

Recebido em: 23/10/2014 Aprovado em: 12/12/2014 